\section{SALT-CARE IN DYEING.}

Written for the Scientific American by DR. M. REIMAST.

In England, as well as in Germany, salt-cake, or sulphate of soda, has been employed for som

as an expedient in dyeing wool.

The practical dyer, when asked concerning the advantages of this substance, which seems to possess so little importance, for the dyeing process, can state no reasonable ground for its employment, only in rare cases you will perhaps hear that employment, only in rare cases you will perhaps hear that it. Even the chemist, on regarding the matter somewhat it. Even the chemist, on regarding the matter somewhat
superficially, does not observe what purpose the sulphate of superficially, does not observe what purpose the sulphate of
soda serves in the dyer's bath. He considers it one of the number of utterly useless substances employed by the dyer in accordance with the prescriptions of some hand-book.

Nevertheless, if we regard the matter carefully in the following discussion, we shall see that sulphate of soda can be of the very greatest value in dyeing processes, and that its employment is based on the most interesting chemical and physical principles. At the same time we shall be obliged to theory, the practical use of which we shall soon recognize.

The sulphate of soda, which is scarcely ever treated of in books on dyeing, because of its chemical indifference for coloring matters, elevates, as every soluble substance does, the oring matters, elevates, as every soluble substance does, the
specific weight, and thus also the boiling point of the solution. specific weight, and thus also the boiling point of the solution.
This property already, when taken into consideration, renders This property already, when taken into consideration, renders
it important for many dyeing processes. It is possible, for instance, to change the shade of aniline violet into blue or red stance, to change the shade of aniline violet into blue or red,
according as the temperature of the solution is more or less according

elevated. very frequently add sulphuric acid to their baths), the sulphate of soda combines with the free sulphuric acid in the bath, and forms with it bisulphate of soda, a crystallizable solid salt. In this manner the bath retains its acid reaction without the presence of free sulphuric acid in the bath. Hence, when half-woolen cloths are dyed, the cotton in them, exvery well preserved.

Dissolved in water in great quantities, the sulphate of soda diminishes the capacity of the bath to dissolve the added coloring matters in as great a degree as though there were no such salt present; this, too, is highly important for many dyeing processes.

Several practical examples will demonstrate the advantages of sulphate of soda more conclusively than a whole series of theoretical obsorvations. The red coloring matters as the
cudbear, and more especially the magenta, and the red dyeing woods, possess, as is well known, the property of combining only with the greatest difficulty with the fiber when dyed in an acid bath. Therefore, wherever the substances are employed in the acid bath-and often this is necessary--the greatest part of the coloring matter is wasted and lost if the common process

If, however, the said coloring matters be dyed in an acid bath according to this new method, a twofold result will be attained. By adding sulphuric acid, the dyeing power of the said pigments can be put into activity, and by varying the quantity of sulphate of soda which is employed, it is possible to control the combination of the pigment with the texible to control the combination of the pigment with the texible
fiber. Therefore, by means of the sulphate of soda various fiber. Therefore, by mean
shades can be produced.

This fact is of great importance in many sorts of dyeing. There are some kinds of yarn, especially the long slubbing wool, which have the property of felting when exposed too frequently to a change of temperature; they can then no longer be worked into weft yarn. Nevertheless, the wool
must be exposed to such a change of temperature, for, in premust be exposed to such a change of temperature, for, in prenew coloring matter may be added to the part already in the bath.

In all these cases it would be unnecessary to take out the yarn if we were to add a little more coloring matter and acid, and shades could be produced by gradually adding sulphate of soda to the bath. By this process a great deal of manual soda to the bath. By this process a great deal of manual
labor may be spared, and the dyer enabled to work with far
more security and comfort. Should at any time too much coloring matter have gone upon the fiber, the fault can readily be corrected by the addition of a little acid.

The truth of the above assertions is most easily perceptible in dyeing Magenta. $\Lambda$ s another example, let us regard the solution of a chrome salt, in the most cases in bichromate of potash. This is often done for rewn, brown and gray, which are produced by means of logwood, red and yellow wood. When the wood is boiled in a bath of bichromate of potash,
and especially when to this, as is commonly the practice, sulphutic acid is added, the colors of the logwood and red wood attack the fiber very quickly, and therefore often spread unequally Hence, dyers must begin to dye at low temperatures, and must increass the heat very slowly. If to such a dyecoloring matters in it is almost nothing, it is, therefore, possicoloring matters in it is almost nothing, it is, therefore, possispreading of the coloring matters. It is only necessary to spreading of the coloring matters. It is only necessary to
add, while the coloring matter is fixing on the fiber, sulphate of soda in small quantities, the coloring matter will combine with the fiber, while the sulphate of soda absorbs the free acid. It is therefore possible to produce shades without re-
moving the goods from the bath, if we take care that the moving the goods from the bath, if we take care that the
quantity of coloring matter which is at first added to the bath is not too small.

A similar effect can be produced by adding the sulphate of soda at the beginning of the dyeing process. For sulphate of $\mid$ 5th. Pyrolusite, the most useful andabundant ore of mangasoda we may, in this case, employ even common salt. In nese, derives its name from two Greek words signifying "fire"
this case the salts employed will, when dissolved in the fluid, and "to wash", in allugion to its property of dischargingth precipitate the dissolved coloring matter, which is then con- brown and green tints of glass ;it crystallizes in small rectan tained in the bath, in a very fine state of division, or the salts gular prisms, or is fibrous, radiated, and divergent, of iron \begin{tabular}{l|l} 
tained in the bath, in a very fine state of division, or the salts & gular prisms, or is fibrous, radiated, and divergent, of iron \\
will prevent the coloring matters from dissolving, according & black color and grayish streak, has a specific gravity of 4:94,
\end{tabular} ath.

For the process this is quite indifferent. The pigments fix on the fiber in the same measure as they are dissolved.
Fresh coloring matter will only then be dissolved, when the portion already in dissolution is already consumed. The dyeing is more equal, if the coloring matters are not dissolved in the bath, but are centained in it in a state of minute division, as every dyer knows who has over employed aniline blue, soluble in water. This pigment, because of its ready solubility in acids, often fixes too quickly if the dyejog is carried on in an acid bath, and therefore dyes at times unequally. It is therefore best to dye from a neutral or weak alkaline fluid,

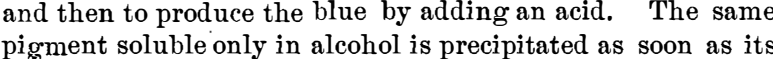
solution is added $t$, the bath, and therefore,dyed more equally, though more slowly still. In many cases also it is advantag. though more slowly still. In many cases also it is advantag-
eous to employ sulphate of soda where ${ }^{2}$ small quantities of eous to employ sulphate of soda where'small quantities of
indigo o carmine are used to g: $v$ 'somewhat more of blue to at ndigo carmine are used to g. $v$ 'somewhat more of blue to a
hade. The affinity of this coloring matter for wool being ery great, small quantities of it may often dye the woolen
oods very unequally; to prevent this, and give uniformity goods very unequally ; to prevent this, and give uniformity
to the color, it is necessary to continue the boiling operation for some time. The indigo carnine will dye more slowly and
equally in the case of the free acid is carried off by sulphate equally in th
of soda.

The question now remains whether only the sulphate of soda, the importance of which I have endeavored to prove in he precoding remarks, is able to produce thase results, In the preceding I already mentioned common salt as a subtitute; and it can be advantageously employed, if either a higher specific weight $c: n$ be produced, or the dissolved colring matter be precipitated.

When common salt is employed in an acid bath, the devel opment of hydrochloric acid is highly disagreeable. Cotton
is violently attacked by it. Common salt can in turn be replaced for these processes by sulphate of magnesia and other
plate salts which exercise no effect on the chemical constituents of
the coloring matters, as, for instance, the compounds of alumthe coloring matter,
ina, iron, and tin.

Similar to the effect producèd by the sulphate of soda, is hat of the corresponding combination with potash, viz.: the sulphate of potash: This salt, however, is more expensive
than the soda-salt. The bisulphate of potash is now already frequently employed in dyeing. The bisulphate of soda, which is a residium in somechemicalmanufacturing processes, for instânce, in the production of nitric acid can often be a To compare the expense of the employment of these substances, we must therefore observe that the sulphate of potash stances, we must therefore observe that the sulphate of potash
crystallizes without water, while the sulphate of soda contains crystallizes without water, while the sulphate of soda contains
55.9 per cent, and the sulphate of magnesia 51.22 per cent of 9 per cent, and the sulphate of magnesia 51
water, which is of course devoid of any value.

Finally, we must state that 100 parts of crystallized sulphate
. soda are able to fix $30 \frac{1}{2}$ parts of sulphuric acid (of $668 \mathrm{~B}$ s. w ), and thus to form bisulphate of soda ; or, in other words,
for every pound of sulphuric acid added to the bath, three for every pound of sulphuric acid added to the bath, thre
pounds of crystals of sulphate of soda must be employed. MANGANESE----ITS USEFUL APPLICATIONS IN THE ARTS BX DR. $\mathrm{D}$. FEVCHTW $A$ NGRR.
This mineral substance was known in ancient times under the name of "glassmaker's soap " and was considered a species oxide of a separate metal, and in 1774, Gahn obtained the pure metal from the native carbonate, exposing the same to intense
heat for several hours, or by subjecting chloride of manganese to electrolysis. Boerhaave does not appear to have known the metal. In my English edition of 1753 he speaks of it in
the following words: "Take the frit and set it in melting the following words: "Take the frit and set it in melting
pots in a working furnace, adding in each pot a proper quanpots in a working furnace, adding in each pot a proper quan-
tity of a blackish stone not unlike loadstone, and called manganese, which serves to purge off that greenish cast natural to all glass and to make it clear." Scheele, Bergman, Chev reul, Berthier, and Berzelius, have in modern times investigated the physical and chemical characters of manganese. The
ore is widely distributed over our globe; it accompanies many iron ores, particularly the hematites, also the franklinito of New Jersey. It has been detected as a constituent of meteoric iron in the ashes of most vegetable and many animal substances, is the coloring principle of many fossils in a den-
dirtic form in the chalcedony which is called the "moch stons," and in the same form on sand peblles of which I found plenty in Stanislaus River in California. It also occurs comatomic proportions of oxygen, such as protoxide, sesquioxide. binoxide, manganic acid, and permanganic acid becoming binoxide, manganic acid, and permanganic acid becoming
thereby sometimes a base and sometimes an acid. The printhereby sometimes a base and sometimes an acid. The prin-
cipal varieties of manganese found in nature are of the followg descriptions

1st. Hausmannite has the form of a four-sided
crystal, with hardness 5 , and a specific gravity 4.7 .

2d. Braunite is an anhydrous sesquioxide, crystallizes in an tahedron, is much harder than the last, and has a higher pecific mavity.

3d. Pulloncilanc; generally called the compact gray oxide stalactitic shapes hombic prisms. and is composed of 37 per cent oxygen and 63 per cent man-
ganese. This ore is generally called binoxide, deutoxide, or peroxide, is a good conductor of electricity, and strongly electro-negative in the voltaic circuit. When heated to redness
it readity parts with its excess of oxygen as it gives off one it reatity parts with its excess of oxygen as it gives off one
third of it. When heated with sulphuric acid one half of its xygen escapes. Owing to this property it is more employed in the arts than any other oxide; it is called in trade the “ black oxide of manganese." Its commercial value is dependant upon the proportion of oxygen which it contains in excess of that which is necessary to its existence as sesquioxide. A founded upon the circumstance, that the black oxide of manganese is decomposed in the presence of oxalic acid, and from sulphuric acid proto-sulphate of manganese is formed, and all the excess of oxygen reacts upon the oxalic acid and converts
it into carbonic acid which passes off with effervescence. If into carbonic acid which passes off with effervescence.
the mixture be weighed before the decomposition has been he mixture be weighed before the decomposition has been
effected, and again after it has been completed, the loss will indicate the amount of carbonic acid; each equivalent of perxide of manganese gives two equivalents or its own weight carbonic acid.

Manganic acid is known under the name of chameleon min eral, is obtained artificially by fusing the peroxide of manga-
nese with equal weights of caustic potash, which when dis solved in a small quantity of water has a green color, but when largely diluted becomes purple and ultimately claret color ; for
in the arts.

Permanganic acit is artificially obtained by mixing intimately four parts of finely powdered peroxide of manganese with three and one half parts of chlorate of potash, while five parts of hydrate of potash are dissolved in a small quantity of water and added to the above mixture, the whole is evaporawater and added to the above mixture, the whole is evapora-
ted and reduced to powder, then heated to dull redness for an ted and reduced to powder, then heated to dull redness for an
hour in an earthen crucible and when cold the mass is treated hour in an earthen crucible and when cold the mass is treated
with water and filtered through a funnel plugged with asbestos ; the solution after being neutralized with sulphuric acid yields on evaporation beautiful red acicular crystals of per-
manganate of potash. This preparation of later years has bemanganate of potash. This preparation of later years has be-
come an important vehicle for disinfection. Among the other native oxides of manganese may be mentioned the mineral wad which is also very abundant but not valuable enough to produce gas. It is amorphous, soft, black, or brown and purple; when mixed with linseed oil it produces spontaneous the dendritic delineations to be the coloring ingredient of steatite and others mentioned elsewhere. The localities of manganese are very prolific; pyrolusite has been mined very exten sively in Europe; psilomelan in England, France, Belgium and the United States ; manganite in Bohemia, Saxony, and England. Much of the latter is consumed in the bleacheries
of those countries. The United States and the Provinces have of those countries. The United States and the Provinces have
inexhaustible deposits of the oxides of manganese. From inexhaustible deposits of the oxides of manganese. From
Vermont, the eastern limit, to Georgia, the southern limit, large supplies were formeriy furnished, but in late years West Virginia, North Carolina, and California have supplied us to a large extent but not of a high grade of oxidation. While
the binoxide of manganese suitable for the manufactures ought to yield from 80 to 90 per cent of oxygen gas, the product of the last mentioned States has not exceeded 50 to 70 per cent oxygen. The provinces of New Brunswick and Nova oxides of manganese, and the specimens I possess in my cabi-
oxidia oxides of manganese, and the specimens I possess in my cabi-
net excel in richness and beauty those from Ilmuran in Thuringen and Ihlefeld in the Hartz mountains of days gone by The manufacturers of bleaching powders in England have for of Nassau to the amount of fifty thousand tuns per annum,
while the United States with all its inexhaustible resources while the United States with all its inexhaustible resources
has not exported any, and it is hoped that betore long the export of manganese may prove lucrative. The quality of the
Nova Scotia manganese is, according to. Howe, of high per centage, some from 82.4 to 89.8 of sesquioxide, and that from Tennycape as high as 97.04 . The international manga-
nese mine of New Brunswick contains from 80 to 85 per cent of sesquioxide. We find manganese in the State of Missour containing much cobalt, while the Vermont manganese is as sociated with much iron. We also find in California, in the red hill of the bay facing the city of San Francisco, containing millions of tuns of psilomelane or compact manganese yielding from 40 to 50 per cent sesquioxide. We also know manganese to exist at Bachawanning Bay on Lake Superior. to exist at Bachawaining Bay on Lake Superior.
The geological position of manganese is not quite accur $\mathrm{r}$ teThe geological position of manganese is not quite accur :te-
known. In Germany it traverses porphyry and is associaly known. In Germany it traverses porphyry and is associa-
ted with calcspar and baryta. In Vermont, in the United States, it is found among crystalline rocks ; in Canada it is accompanied by dolomite, and in Nova Scotia it exists in a gray limestone, quartzite, and conglomerite, and it unquestionably be-
longs to the new red sandstone formation. My manganese mines at Pembroke are situated close to the gypsum deposits, which would range them with the upper silurian system. I will now enumerate the many u eful applications in the rts.

1st. Manganese is employed for producing oxygen gas in ganate in order to procure a good and cheap light in combina. tion with coal gas. convenient method of estimating this excess of oxygen is The manufacturers of bleaching powders in England have for
the last twenty years been supplied by the little principality has not exported any, and it is hoped that betore long the ex-
port of manganese may prove lucrative. The quality of the the chemical laboratory, the material of the compound blow 

2d. Mnruganse is most extensively ased in the manufacture
of chlorine so as to prepare a bleaching liquid or powder, the consumption

3d. Next in importance is the manganese largely employed in the green flint glass works in precipitating the iron, and when added in excess to produce an amythyst color in flint glass.

4th. Steel manufacturers requiremanganese for producing a hard and tough prodnct; a half pound to fifty of iron will have the effect.

5th. Linseed oil is rendered more siccative by the addition nishes.

6th. A permanent black on earthenware and pottery is obtained by exposure to heat.

7th. A black enamel used in ornaments by jewelers is likewise produced with manganese.

inf. The manufacture of permanganates, a powerful, dis tained from the same.

9th. The quality of spirits, with or withont distillation, is obtained by the use of maganese.

10th. The chameleon mineral used in sugar refining is pre pared with manganese.

The consumption of manganese for the manufacture of the new gas light about to be introduced in this country, forms new epoch in this direction. It is to be converted first into the alkaline manganate, which acting as a sponge alternately absorbing the oxygen of the air and again releasing it, must require if successful, not less than one hundred thousand tuns oxygen gas, and I gather the following pariculars from the programme issued by the inventors, Messrs. Tessie de Motay and Marechal of Metz: "The manganates are decomposed at nary steam which liberates the oxygen and leaves a residu um composed of sesquioxide of manganese and the alkaline base contained in the combination. The manganate is regenerated by submitting the above mentioned solid residue to the action of a current of air at the same temperature as used in the de-
composition, and all these operations are cond ucted in a series composition, and all these operations are conducted in a series
of retorts placed in a furnace where the manganates, after beof retorts placed in a furnace where the manganates, atter be
ing raised to a temperature of $600 \mathrm{deg}$. Fah., are alternately submitted to the action of a jet of steam and current of ai which restores to the mass the oxygen has lost. The oxygen is disengaged by the steam from retorts; this steam is liquified by pressing into a condenser, and the pure oxide is collected
into a gasometer. When applied for the production of light, oxygen in combination with common coal gas permits a reduction in the consumption of the latter, but at the same time giving an equal quantity of light in the proportion of 16 to 1 .
The permanganate of potash or Condy's disinfectantis recommended as a powerful agent in obtaining pure drinking water mended as a powerful agent in obtaining pure drinking water manganese is consumed by the manufacturer of bleaching powders. England alone consumes 80,000 tuns for that purpose per annum, and as soon as the United States becomes independent of the English imported chloride of lime for bleach-
ing the cottons and the papers, not less than one half million tuns will be consumed for the desired olyject, fior on examin-
ing the report of the director of the bureau of statistics, I find ing the report of the director of the bureau of statistics, I find that 12,682 tuns of bleaching powder have been import
first five months of the year at the value of $\$ 324,066$.

\section{NOTES ON THE VELOCTPEDE.}

Our exchanges teem with items of all sorts concerning the velocipede. We are also in receipt of many letters of inquiry and suggestion with reference to the construction of the
machine, some of them unpractical, others containing useful hints. One correspondent suggests the making of a vulcanized rubber rim to velocipede wheels, so that they could be
run over Belgian pavements without shock to the rider, and the propeller wheel could also gain superior tractive power. Some very ingenious and peculiar devices are now on their this little iron horse " a horse of another color "if we mistake not in our predictions.

A lady, writing from Georgia, wishes manufacturers to take into special consideration the wants of ladies. She says that the awkward position they are now forced to assumeastride the front wheel, is a serious objection. She suggests a veloci-
pede for two persons. It might have seats something like pede for two persons. It might have seats something like
side-saddle facing in opposite directions and be propelled the combined power of the two riders, each on her own side of the wheel. This suggestion is worthy consideration but, for our own part, we don't think it would work well with two female riders. There can be no doubt, however, that good sport could be had by a gentlemen and lady on a ma-

ention, there are those who wish to make out that it is a discarded experiment of the past; but we do not believe the velocipede of the past could compare either in principle or nicety?

We two-wheeled machine of the present.

We have in our office a colored engraving of the velociped This machine was of the most jimple as follows :

This machine was of the most simple kind supported by two
light wheels running on the same line; the front wheel turnlight wheels running on the same line; the front wheel turn-
ing on a pivot which, by means of a short lever, gave the di-
rection in turning to one side or the other, the hind wheel always running in one direction. The rider mounted it and seated himself in a saddle conveniently fixed on the back of
the horse (if allowed to be called so), and placed in the middle
between the wheels ; the feet were placed flat on the ground, so
that in the first step to give the machine motion the heel should that in the first step to give the machinemotion the heel should
be the part of the foot to touch the ground, and so on with the other foot alternately, as if walking on the heals, observing
always to begin the movement very gently. In the front before the rider was placed a cushion to rest the arms on while
the hands held the lever which gave direction to the machine as also to balance it if inclining to either side when the oppo-

It will be seen at once that the "little difference" in the letely changes the modern one, comwhich assailed this machine was not without foundation; the motion in propelling it was not graceful, and it was said give rise to numerous cases of rupture. Not so with the velocipede of the present, which glides
along as though it were alive, and with a smooth grace alike exhilarating and beautiful to behold.

An English paper gives a description of a velocipede calculated to convey from six to a dozen people. It has four wheels
for carrying and propulsion, and a fifth guide wheel, which acts upon a lever or pole, and cramps two of the wheels precisely as the fore wheels of carriages are not cramped in turning. Each pair of carrying wheels is provided with double cranks which are connected with each other by longitudinal This velocipede is provided with cross seats having backs like
treadle bars, so that all can aid in propelling the machine. This velocipede is provided with cross seats having backs like
one of our Yankee market-wagons. It has not been tried yet, one of our Yankee market-wagons. It has not been tried yet,
but it is stated that a club is being organized to manipulate it. Berformances with them are coming into fashion at the theaters. In the Parisian theatrical world considerable sensa-
tion has been caused by velocipede performances, and even some curious acrobatic exercises are gone through with them. A notice in the Paris journals recently stated that not more than twelve velocipedes should be allowed "at one time" on the stage. Chicago has followed suit, and the habitues of
Crosby's Opera House have been treated to velocipede exhibitions between the other portions of the entertainment.

There also was a velocipede race at Rike's Music Hall in thefastest rider,and another,also worth $\$ 100$ to the slowest rider An exchange says, thet a day or two since, a certain gentleAn exchange says, that a day or two since, a certain gentle
man in Chicago, who has been practicing for some time on the side.walks, at vespertinal hours, came out upon Indiana avenue, and throwing down the gauntlet of defiance, dared a
street car driver to race with him to Thirty-first street, the terminus of the track. The challenge was gallantly accepte by the car driver, although the latter had several lady passen
gers on board. The race began auspiciously, the horses being gers on board. The race began auspiciously, the horses being
driven at a furious pace. The velocipede soon gained upon its competitor and bade fair to distance it when an unlucky crack in the sidewalk received the fore wheel, leaving the other, in obedience to the law of its momentum, to turn a somersault "foul"

Rural districts are catehing the mania. A velocipede school has, we learn, been established +in Bridgeport, Ct., but it is said that the nearest approach to a velocipede that has been
seen in Danbury was a bit of orange peel, on whick a citizen went across a sidewalk and down a pair of stairs ir jut $1 \frac{1}{4} \mathrm{sec}$ onds-the quickest time on record.

Winslow Homer's last drawing for Harper's Weekly is very
original in conception. He makes the New Year come in on velocipede!

Mr. Dana, of the Sun, has become, it is said, one of the most expert velocipedists in the city. It is also asserted that hear vocates a project to build an elevated railway from Harlem to the Battery, to be used only by the riders of velocipedes. By this means it would be possible to go from one end of Manhat
$\tan$ Island to the other in about an hour, making allowance or delays from stoppage and accidents. A good rider, with clear track, would easily accomplish the distance in half an hour; but, with a well-filled road, progress would necessarily be slower. The proposed roadway ought to be at least thirty
feet wide, upon an iron framework; with a flooring of hard feet wide, upon an iron framework ; with a flooring of hard
pine. By all means let us have the "elevated roadway," and pine. By all means let us have the "elevated roadway," and
let the sidewalks be kept clear for pedestrians, who are otherlet the sidewalks be kept clear for pedestrians, who are other-
wise likely to be endangered by the carelessness or awkwardwise likely to be end

We regret to record that the Park Commissioners have pro hibited velocipedes in the Park. The reason assigned is that the drives are narrow and horses are likely to become fright
ened. Then, why, Messrs. Commissioners, do you not widen the drives without delay? The Park was made for the public not the public for the Park. The drives are too narrow, anyway, especially on the east side of the Reservoir, and as we
believe it is intended to widen them, we not see good cause believe it is intended to widen them, we do not see good cause
for postponing the vrork. A sto frightening horses the follow$\mathrm{ng}$, from a correspondent of the Herald, is practical and sug gestive:

The Herald is right. Velocipedes ourlat to be admitted to
the Park. And why not? In theyear $185 \pi$ I spentnearly four months in Paris, and occasionally saw velocipedes passing rapwithout exciting much attention either from man or beast
The horses did not appear to notice them at all. I was in Paris The horses did not appear to notice them at all. I was in Paris
again last spring and found the velocipede mania raging with upon the most frequented streets and public places of the city
The horses were not afraid of them. Yet, if you will allow me The horses were not afraid of them. het, if you will allow me
to say so, I am not quite sure that this state of things would
hold good in our parks. It is noticed by all travelers that a hold good in our parks. It is noticed by all travelers that a
runaway is a rare occurrence in Paris. Indeed, this remark holds good respecting all other cities in Europe. I have spent
nearly two years of my life in Europe, and in all that time I
never saw a horse run away. On my first visit to the Park afnever saw a horse run away, On my first visit to the Park af-
ter my return, in June last, I saw the fragments of no less than
threelight geared, heavy top buggies scatter ad along the roadthree light geared, heavy top buggies scattered along the road-
way, and it is not uncommon, I am told, to have ten or fifteen
injirregl persons brought in on a single day to St. Luke's Hospiujuresl persons brought in on a single day to St. Luke's Hospi-
ual, victims of smash-ups in the Park. There is something radically wrong either in our driving o
in our system of breaking horses. Probably both are faulty
And here, I suggest, is a subject for a searching inquiry.
Adulterations in Tea and coffee.

The New York World has been applying its editorial nose the tea chests and coffee bags, as well as the whisky barWe heard York, and finds much to offend. It says Wh in a cargo of damaged tea from a vessel which sunk in the harbor. It was properly doctored and fixed up, and put
into the market afterwards. A common adulterant of genuine teas is exhausted tea leaves. A few years ago there were
eight manufactories for the purpose of re-drying exhausted tea leaves in London, and several others in various parts of tho
country. The practice pursued was as follows: Persons were country. The practice pursued was as follows: Persons were
employed to buy up the exhausted leaves at hotels, coffee
houses and other places at 21 1-2d. to $3 \mathbf{d}$. per pound. These were taken to the factories, nixed with a solution of gum, and re-
dried. After this the dried leaves, if for black tea, were mixed with rose pink and blacklead, to " face" them, as it is termed the trade. The same practice is pursued in this country.
Perhaps the most general mode of adulterating the better
rades of coffee in New York is by the admixture of inferior coffee. The Java is, of course, rich and comparatively expensive. The common South American coffee is cheap, has a flat
aroma, and a bitter taste. When the berry is burnt it cannot readily distinguished from the Java berry, and, of course,

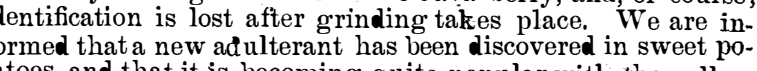

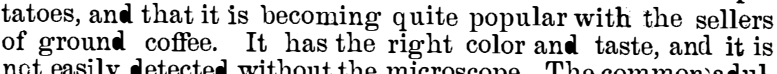
of ground coffee. It has the right color and taste, and it is
not easily detected without the microscope. The common adul-
terant for coffee, however, is chicory. The use of chicory is
openly acknowledged in some places, and even defended by
grocers on the score of health and economy. grocers on the score of health and economy.
We have medical testimony that chicory is extremely injurious to health. Dr. Hassall says that taken constantly, prosthach, loss of appetite, acidity in the mouth, constipation
with intermittent diarrhea, weakness in the limbs, trembling, sleeplessness, a drunken cloudiness of the senses, etc. Again,
it is the opinion of an eminent oculist in Vienna, Professor Beer, that the continual use of chicory seriously affects the
nervous system, and gives rise to blindness from amaurosis. nervous system, and gives rise to blindness from bamaurosis.
Its use ought, therefore, to be discouraged, and grocers who sell

\section{An Earthquake Conventiom.}

A convention called by joint committee, on the Investigation of Earthquakes, has heen held in San Francisco, with a riew to the adoption of an improved system of building and other precautions against future disaster from earthquakes.
The following report of its proceedings is from the Bulletin: Mr. Gordon explained that the laboring oar in the investiga-
tion must fall on the two secretaries, and gentlemen had been selected having peculiarqualificationsfor the position, and who
could give their entire time to the business in hand. Profescould give their entire time to the business in hand, Profes-
sor Rowlandson would bring the experience and critical knowl-
edge of a man of science, and Mr. Bridge, a practical arehitect edge of a man of science, and Mr. Bridge, a practical architect
and builder, a vast fund of information in relation to investiga-
tions and experiments with mortars, cements, etc., gained while with General Gilmore, United States army.
The President called for reports from the stb-committee No. 1, on bricks, stone, and timber.
General Alexander, chairman

General Alexander, chairman, reported that the committee
had made some preliminary investigations as to the qualities of brick, and had put on foot inquiries as to the propert esof brick
made mostly from sand, which had been highly spoken of in made mostly from sand, which had been highly spoken of in
the Eastern States. He had no hesitation in saying that, as $~$
rule, the brick used in the city were not good. Better brick can be made with the same material by using proper propor-
tions and knowledge in burning, etc. He cited from his own experience a case in point, where a large kiln of brick had
been condemned as defective, and from the same material, under his supervision, a very superior article had been made; the difference being in proportions and in burning.
Sub-committee No. 2. on Limes, Cements, Mortars, etc.,
colonel Mendel, chairman, reported that they had the matter
in progress, but were not prepared to make any extended rein progress, but were not p port. Granted further time.

Sub-committee No. 3, on Structural Designs, General Alex-
ander, chairman, reported progress from the committee whe ander, chairman, reported progress from the committee, who
were granted further time.
The President rnade some incidental remarks on the adviswere granted further time.
The President rnade some incidental remarks on the advis-
ability of recommending some plan by which structures already erected can be strengthened by iron bracing, to resist any sub.
sequent shocks, instancing the plan he was adopting in bracing the sugar refinery, etc. The matter was discussed by General
Alexander, Colonel von Schmidt, Dr. Blake, and Judge Rix. On motion of Mr. Iix the matter was referred to the Committee on Structural Designs.
Sub-committee No. 4, on Scientific Inquiry, etc., Dr. James Blake, chairman, reported that the committee had met, and the ter was read by General Alexander from R. C. Hopkins, Custostating that the archives were at the disposition of the committee in any investigation they might wish to make, and
offering his services as translator, etc. The matter was referred

to the same committee.
A discussion followed on the value of these old records on
the subject under consideration. From remarks made by Prof. Rowlandson, it appeared that the old Mission records had been
pretty well searched by Dr. Trask, Dr. Tuthill, and others. Mr. ITittell, of the Aita, stated that he had personally inspected them very meager and unsatisfactory. On motion of Major
Elliot, Colonel Williamson, United States Engineer, was placed on the Committee on Scientific Inquiry.
A letter was received from W. Frank Stewart of San Jose, the gathering of facts connected with the earthquake in the the gathering of facts connected with the earthqu
vicinity of San Jose, was intrusted to Mr. Stewart.

Food REQuired to SUSTAIN LifE.-Judging from the mintmum quantities of tood upon which an ordinary individal is capable of existing without suffering in health, it would seem that about 4,100 grains of carbon and 190 grains of nitrogen are required in his daily diet. These proportions as by those of Dr. Lyon Playfair, in his inquiries into the dietaries of hospitals, prisons, and workhouses, and by those of Dr. Edward Smith, in his examination of the amounts of food
upon which the Jancashire operatives were capable of living durng the cotton famine, and also by his inguiries into the dietsrien of indoor laborers. 